\title{
Approaches to the Presentation of English Word Meaning
}

\author{
Zhang Yu \\ Xinyang Agriculture and Forestry University, Xinyang, Henan Province
}

Keywords: enrich the connotation; approaches; broaden mind

\begin{abstract}
Various ways are applied in the interpretation of English words, such as giving the definition of a certain word by illustrate its synonyms, or setting up a situation in which vivid symbols or pictures are shown as a detailed explanation which turns abstract to concrete. Factually, English learners have mastered them more or less, but few try to analyze the approaches which are of great use in optimizing expressions, broadening mind, and diversifying the ways to enrich the connotation of a word. Here the author tries to summarize some specific approaches to English word meaning, hoping the experience can be helpful for those who are willing to know more about a single word and change the way we think. Though this paper is not elaborated in an all-round way, at least the aim is clear, namely to provide reference for further study in this realm.
\end{abstract}

Inspiration for creating this paper originates from a question given by another English enthusiast, that is "Could you please translate '可望不可即' ? (It refers to something that seems so close to you, but it is hard or impossible to seize) ". A definition goes like that according to the dictionary, "Having or exhibiting something that provokes or arouses one's expectation or desire, especially which remain unobtainable or out of one's reach." Being interpreted like that, it is pretty clear to most of the English learners, however, some unsolved confusion still exist due to the differences between Chinese and foreign cultures. Thus, a vivid way to explain it is also needed if we intend to start from an all-round perspective. It is so accidental that another translator expressed it as "Pie in the sky' which is similar with the expression of "Luna in the water", building a concrete scene that greatly enriched the connotation of the word. The relations between these two expressions should not be contradictory but should tolerate each other, promote the expansion of the word, and together constitute a grand universe for us to explore.

\section{The Significance of Digging Various Ways to Explain a Word}

Obviously, it is for Cultivating Students' Activeness and Imagination and Realizing "Open-minded" Target. Two questions must be considered as the foundations for researching this issue, namely whether the way of an English learner tries to explain and remember a word is in accordance with his personality and his own way of thinking, and whether our mind is being locked when we tries to follow the way of interpreting a word as others tell us.

In general, the author himself is accustomed to adopt different methods to explain the meaning of a word when he encounters diverse conditions. Of course, some other means are also widely used in the understanding the same word for others, as the life of everyone is unique and the rainbow emerges at different time of the stage, and that is why the world is so colorful, glittering as our minds.

If a word is interpreted in an only way that everyone has to recognize and understand it by following the same principle, it does not conform to the fact that everyone has his own personality and characteristics in learning, and the competence of each is distinguished from others'. Here is an argument "Socialism with Chinese characteristics", which properly elaborated the essence of the individual's difference in recognition. Maybe the definition of a word is relatively easy to understand for one, but in the eyes of another, he thinks that it is impossible to understand and remember the meaning of the word because its explanation seems too abstract for him, so he wonders whether there is a specific example that can help him to be approachable to it. 
In another case, a teacher who regards a single way of learning word as absolutely correct and cherishes his authority, by giving several complicated words that the students also haven't mastered yet to constitute a definition to explain the word, hoping that it will be accessible to the students' brains. However, a student could have related a new word to something interesting that ever had happened in his life and was about to remember it. However, in a statue that things haven't been done, he was more or less disturbed by the teacher's instruction and his own thoughts died. It is not the time to judge whether the teacher should change his stubborn views, recognize the distinct ways to remember words, and even advocate different ways according the student's factual condition; we should not criticize the student that he is not able to persist in his own way of learning. It is a fact that great importance should be attached to, that is the locking of our minds, thoughts that should have flied to a boundless sky, which are now being constrained in a limited space. It is not the right way to motivate students to release their activity, imagination and vigor. That is not the talent we want to harvest at the right time.

If these two issues are clear now, it is easy to transform our way of learning. First of all, we must recognize the fact that everyone has his own way to understand and remember as his knowledge storage varies due to the experience attained in his growth, then respect the law of nature, and encourage the students to think more, try new methods to enrich the connotation of the English words. Obviously, what the author intends to emphasize here is similar to the opinion of "open-minded", it is the right way to interpret it. As an English learner, or the seeker of language's beauty, enthusiasm, persistence, imagination, creativity together constitute the significant spirits in learning English.

The author wants to prove his argument by giving some information about another issue, but the essence of the questions remains the same. For translation practice and theory, a lot of scholars stress on the importance of translation practice in doing translation work, but those such as Newmark and Eugene Chen Eoyang had ever given their different views, demonstrating that translation theory is not necessary for a good translation or its survival. There are great disputes in this issue, as a significant topic that calls great attention, scholars support their statements about it with their evidence, which made the research meaningful. So for a simple one, different opinions should be tolerated in an easier way. By comparing these two issues, the author believes that the necessity of different thoughts and ways in learning English words should be advocated and encouraged.

\section{Specific Examples of Interpreting the Meaning of the Word}

After showing the basic foundation for this argument, then comes the second part, in which some examples in the practice are listed as the evidence.

We can take the word "destruction" as the first example. In the dictionary, it is explained as "the termination of something by causing so much damage to it that it cannot be repaired or no longer exists", it does make sense, and the learners usually understand it as a state that something is totally broken or is brought to an end by force or violence. But "something" is still not clear or concrete enough for some, so whether there is a better approach to the word? Now assume that we present a series of pictures; dinosaurs brag about their dominion as the absolute overlord in the first one; the second one shows a scene that unstoppable and irreversible disasters caused by geological activities such as debris flow and volcanic eruption are destroying the world, or rebuilding its order, if we plan to describe it in a gentle way. Then attention is drawn to the third one; without any vitality, the dead silence claims the end of dinosaurs' era. That is a different way to interpret the word "Destruction".

That whose brain has been already occupied by the thought of judging which one is better is not qualified to be a good explorer in the realm of English learning till now, or at least, his mind is not thoroughly broadened. What we should do is to try to find more or even create other new ways to explain the meaning of this word.

Sometimes, we need to find a reference and interpret a new word by comparing it with the chosen word that we have already known. For example, transformation is distinguished from 
change from the degree as it is explained as "A complete change in sth." So what is a complete change? Or in which way can we get closer to its meaning? According to the observation of the author, many teachers and students are apt to compare "Great changes have taken place in China over the past years" and "China has witnessed a transformation in past decades." These two sentences are definitely close in the meaning, and the variation in word choosing has reflected the difference in meaning between the word "transformation" and "change". Usually, we define that much more than average in degree or quantity as great, so "great changes" is similar to a degree of "dramatically changed", in the second sentence we listed above just now, "great changes" is replaced by "transformation", so it is apparent that transformation can be described as a great, dramatic, or total change. Here "change" is chosen as the reference for comparison, and we can also give an example in which comparison is also contained to better support our argument.

A man tries to start a relationship with the lady he likes, though he is a self-centered man with bad temper, he can pretend to be humble, gentle and tolerate every time he dates with the lady, and after appointments he will return to the original, and he thinks that once the lady accepts him, it is not necessary to disguise any longer. We can say the change presented in front of the girl is what he made rather than that he is, so it is a change and just a change to gain more good affection. However, if the rude man who always concerns with himself without caring others is influenced by the kind lady, he cherishes her, and is willing to break off his bad habits and try hard to be a dispensable part of her by heart, he rebuilds himself to a totally new person who can be a reliable husband, that is called "transformation", and a complete change in his character has emerged.

By comparing with the simple word "change" and illustrating the case in which two different statues of a man are presented, we have an intuitive understanding of the word "transformation", and that is the way the authors hopes to spread to more learners to get an easier access to the meaning or even the connotation of a word.

\section{References}

[1] Istvan Kecskes. Contextual Meaning and Word Meaning [J]. Foreign Language, 2006(05):18-32.

[2] Zhang Yuxi. Word Meaning by Context in English-Chinese Translation[J]. Higher Education and Academic Research, 2006(01):30-34.

[3] Xiao Jiugen. Research on the Features of Ancient Word Meaning in Chinese Dialect_— Taking the Features of Word Meaning in Gan Dialect as an Example[A]. Proceedings of The 3rd International Conference on Social Science and Higher Education (ICSSHE-17) (Advances in Social Science, Education and Humanities Research VOL.99) [C], 2017:3. 